\title{
A reforma universitária e o Departamento de Matemática da UFMG
} (1969-1977)

\author{
University reform and the Department of Mathematics at UFMG (1969-1977)
}

\author{
Maria Laura Magalhães Gomes ${ }^{1}$ \\ Maria Cristina Costa Ferreira ${ }^{2}$ \\ Helder Cândido Rodrigues ${ }^{3}$
}

\begin{abstract}
Resumo
Este artigo aborda a trajetória do Departamento de Matemática da UFMG em seus primeiros anos após a reforma universitária de 1968. Apresenta-se inicialmente um panorama histórico dessa universidade antes da reforma, com destaque para os antecedentes do referido Departamento. Com base em documentos institucionais e em entrevistas de antigos professores, objetivou-se investigar, nos momentos depois da reforma, três aspectos específicos e inter-relacionados essenciais à modernização universitária: a capacitação docente, o regime de trabalho e a implantação da pós-graduação em Matemática. O mestrado em Matemática na UFMG, implantado em 1971, resultou de esforços de várias pessoas e possibilitou a capacitação dos docentes do Departamento na própria UFMG. Ficou evidente a vinculação entre a estruturação departamental e a pós-graduação, cujo sucesso resultou de políticas internas do Departamento que estimularam a capacitação dos professores pela realização do mestrado em Matemática.
\end{abstract}

Palavras-chave: Reforma Universitária; Departamento de Matemática da UFMG; História da Educação Matemática; Capacitação Docente; Pós-graduação em Matemática.

\begin{abstract}
This article discusses the trajectory of the Department of Mathematics at UFMG in its first years after the university reform of 1968. A historical overview of this university before the reform, highlighting the background of that Department, is initially presented. Based on institutional documents and interviews with former professors, the objective was to investigate, in the moments after the reform, three specific and interrelated aspects essential to university modernization: teacher qualification, the work regime and the implementation of postgraduate courses in math. The master's degree in Mathematics at UFMG, implemented in 1971, resulted from the efforts of several people and enabled the qualification of the Department professors at UFMG itself. The link between departmental structuring and graduate studies became evident: the success of the
\end{abstract}

\section{Submetido em: 25/05/2021 - Aceito em: 11/07/2021 - Publicado em: 10/12/2021}

1 Doutora em Educação pela Universidade Estadual de Campinas. Bolsista de Produtividade do CNPq. Professora do Departamento de Matemática e do Programa de Pós-Graduação em Educação da Universidade Federal de Minas Gerais, Brasil. Email: mlauramgomes@gmail.com. ORCID: https://orcid.org/0000-00032423-7750.

${ }^{2}$ Doutora em Educação pela Universidade Federal de Minas Gerais. Professora aposentada do Departamento de Matemática da Universidade Federal de Minas Gerais, Brasil. E-mail: mcristinaferreira@gmail.com. ORCID: https://orcid.org/0000-0001-6329-1982.

${ }^{3}$ Doutor em Matemática pela Universidade Estadual de Campinas. Professor do Departamento de Matemática da Universidade Federal de Minas Gerais, Brasil. Email:xhelder@ufmg.br. ORCID: https://orcid.org/00000003-2776-7482. 
DOI: $10.20396 /$ zet.v29i00.8665754

postgraduation studies in Mathematics in UFMG resulted from the Department's internal policies that stimulated the qualification of teachers by conducting a master's degree in mathematics.

Keywords: University Reform; Department of Mathematics at UFMG; History of Mathematics Education; Teacher Qualification; Postgraduation Studies in Mathematics.

\section{Introdução}

A reforma de 1968, como ficou conhecida a Lei federal 5540, de 11 de novembro de 1968, modificou radicalmente o ensino superior anteriormente desenvolvido no Brasil pela implantação de muitas e diversificadas medidas que caracterizam o cenário hoje ainda vigente nas instituições universitárias. A lei de 1968 e os vários documentos legais que a precederam, ou seja, as reformas dos anos 1960/1970, conduziram, num contexto de desenvolvimentismo e modernização, mas também de repressão e violência, a profundas mudanças em relação à autonomia das universidades, a sua estruturação, à carreira dos professores e ao ingresso dos discentes. As reformas levaram à ampliação das vagas na graduação, fomentaram a pesquisa e expandiram e normatizaram a pós-graduação incipiente presente antes nas instituições. Novos prédios foram construídos nos campi, criaram-se e equiparam-se laboratórios, institucionalizou-se a profissão docente por meio do regime de tempo integral e dedicação exclusiva (Cunha, 2003; Motta, 2014).

Para Motta (2014), embora tenham sido implementadas durante a ditadura militar estabelecida no Brasil a partir de 1964, as mudanças na universidade vinham sendo debatidas e propostas no país desde os anos 1950 e dois pontos fundamentais predominavam nesses debates. As universidades precisavam mudar por estarem fundadas sobre o modelo arcaico das cátedras, no qual docentes poderosos tinham cargos vitalícios e produziam pouco conhecimento, e professores que ocupavam os cargos hierarquicamente inferiores agiam de maneira apática devido à insatisfação quanto às condições de trabalho. O segundo ponto dizia respeito às transformações do país representadas pelo crescimento da população, da urbanização e da rede de educação secundária nos anos 1950-1960, que configuravam um cenário em que o número de vagas nas universidades era muito inferior à demanda pelo ensino superior. Motta (2014) acentua que, conquanto houvesse convergência quanto à necessidade de modernização e ampliação da produção de conhecimento, projetos políticoideológicos em disputa divergiam sobre os rumos a serem tomados. Sobretudo os estudantes, cuja perspectiva tinha natureza socialista e revolucionária, promoveram debates pela reforma universitária antes de 1964. Segundo Cunha (2003), o projeto de uma reforma universitária pró-democratização nasceu e se desenvolveu no interior do movimento estudantil e foi somente às vésperas do golpe militar de 1964 que um contingente significativo de docentes assumiu esse projeto.

Os adeptos da direita, por seu lado, desejavam mudar o ensino superior para torná-lo mais eficiente e produtivo, tendo como horizonte o desenvolvimento econômico e a modernização da máquina pública. Esses grupos, porém, questionavam a gratuidade do ensino e defendiam a cobrança de taxas dos estudantes que pudessem pagar (Motta, 2014). 
Nesse quadro, é fundamental enfatizar a forte presença da perspectiva de desenvolvimento e modernização, originada principalmente nas ciências sociais dos Estados Unidos. No Brasil dos anos 1950 e 1960, teve imenso destaque o debate político e acadêmico sobre a modernização e o desenvolvimento nacional. A educação se inseria na trajetória da modernização, com a Universidade como um dos pontos inerentes a essa trajetória (Oliveira \& Faria Filho, 2019). A educação era "um dos setores prioritários da pauta modernizadora, por seus efeitos multiplicadores e por incutir valores nos jovens" (Motta, 2014, p. 10). Efetivada no regime militar implantado desde 1964, a reforma do ensino superior integrou o conjunto de estratégias de reforma do Estado e da administração pública em busca da modernização econômica (Vieira, 2016).

Há muitos estudos que focalizam diferentes aspectos da reforma e seus reflexos na educação brasileira em geral, a exemplo de Mendonça (2000), Saviani (2008), Cunha (2003, 2007), Motta (2014), Lüdke (2005), Alves e Oliveira (2014), Vieira (2016). Também há aqueles que se dedicam ao exame da reforma em um contexto específico, como a Universidade Federal de Minas Gerais (Veiga, Albano, Somarriba \& Barbosa; 1987; Oliveira \& Faria Filho, 2019), que abordam os modos como as políticas da reforma foram absorvidas nessa instituição. O trabalho que aqui apresentamos insere-se nessa linha de pesquisa sobre um ambiente particular da mesma Universidade, o Departamento de Matemática do Instituto de Ciências Exatas (ICEx), nascido precisamente após a reforma de 1968. Examinamos os antecedentes desse departamento no interior da UFMG e discutimos alguns resultados de nossa investigação quanto às modificações trazidas aos docentes de Matemática da instituição pela reforma universitária.

As fontes que utilizamos foram de dois tipos: documentos escritos e material proveniente de duas entrevistas com professores aposentados do Departamento. Os documentos escritos foram as atas das reuniões da Câmara do Departamento de Matemática no período 1969-1977, alguns diários de classe de disciplinas da graduação em Matemática e listas de ex-alunos no site do Programa de Pós-graduação em Matemática da UFMG. As entrevistas com os professores Maria Suzana Balparda de Carvalho e Roberto de Maria Nunes Mendes, conduzidas pela segunda e pelo terceiro autor deste artigo, foram realizadas e filmadas em dependências do atual Departamento de Matemática, respectivamente em 06/10/2017 e 20/09/2017. Suzana e Roberto aceitaram o convite para uma conversa baseada em tópicos relacionados aos primeiros anos do Departamento de Matemática do ICEx e nos autorizaram a usar seus depoimentos em nossa pesquisa. Trabalhamos ainda com um texto redigido por um terceiro docente aposentado do Departamento, Pedro Mendes, que respondeu, em abril de 2021, a questões que lhe foram enviadas por email pela segunda autora deste trabalho na mesma ocasião. Pedro também concedeu a nós, autores, autorização para uso de seu depoimento escrito.

Na utilização de depoimentos pessoais, tomamos como referenciais pesquisadores que teorizam sobre a História Oral, a exemplo de Alberti (2006), Garnica (2010) e Portelli (2010, 
$2016)^{4}$. De acordo com esses autores, enfatizamos que essas fontes são produzidas intencionalmente pelos pesquisadores/entrevistadores, coautores das entrevistas, que criam um espaço narrativo para os entrevistados, que não fariam seus relatos igualmente em outro momento, outro contexto ou para outro entrevistador. Neste trabalho, é importante considerar que entrevistadores e entrevistados compartilham um espaço institucional - o Departamento de Matemática da UFMG.

Por outro lado, no que concerne aos documentos institucionais da UFMG em que nos apoiamos, é preciso lembrar que foram produzidos para outras finalidades, a saber, aquelas de natureza administrativa e acadêmica na Universidade. Esses documentos e, em particular, as atas das reuniões do Departamento, os que mais nos auxiliaram, não são neutros; portam as marcas de sua época e de seus autores e como tal foram contextualizados e receberam um olhar crítico de nossa parte, conforme recomenda Bacellar (2010).

Assim, com base em documentação escrita institucional representada por atas, diários de classe e listas de pessoal e usando relatos de antigos professores, focalizamos três aspectos específicos e inter-relacionados essenciais à modernização: a capacitação docente, o regime de trabalho e a implantação da pós-graduação em Matemática. O período de referência iniciase em 1969, com a efetivação da estrutura departamental e constituição do Departamento de Matemática na UFMG. O marco temporal final é 1977, ano em que esse Departamento já se encontrava totalmente modificado, com a renovação de mais de metade do corpo docente original e a consolidação do Mestrado em Matemática implantado formalmente na Universidade desde 1972. Inicialmente, traçamos um panorama dos acontecimentos que precederam a criação do Departamento de Matemática no contexto da reforma universitária na UFMG.

\section{Antes do Departamento de Matemática do ICEx}

A UFMG, com a denominação Universidade de Minas Gerais (UMG), nasceu em 1927, a partir da reunião de quatro escolas isoladas fundadas anteriormente - Direito (1892), Odontologia (1907), Medicina (1911) e Engenharia (1911) -, como uma universidade vinculada ao governo estadual de Minas Gerais. Agregaram-se a ela, nos anos seguintes, outras unidades. Particularmente na segunda metade da década de 1940, houve a incorporação à instituição de outras escolas livres criadas em Belo Horizonte: a de Arquitetura, em 1946, a Faculdade de Filosofia e a Faculdade de Ciências Econômicas, ambas em 1948. A Universidade foi federalizada em 1949 e, após a integração de outras unidades ao longo dos anos (Enfermagem, Veterinária, Biblioteconomia, Belas Artes, entre

\footnotetext{
${ }^{4}$ Devido às limitações de espaço, vamos aqui sintetizar as ideias desses autores com a referência aos quatro pontos a serem considerados elencados por Portelli (2016, p. 12), que compõem o conjunto de relações que alicerçam a História Oral: a relação entre entrevistados e entrevistadores; a relação entre o tempo do diálogo e o tempo histórico discutido na entrevista; a relação entre a esfera pública e a privada; a relação entre a oralidade das fontes e escrita do historiador. O leitor interessado poderá se aprofundar no tema a partir dos trabalhos citados.
} 
outras), teve seu nome mudado para Universidade Federal de Minas Gerais (UFMG), por determinação do governo federal, em 1965.

No início da década de 1960, o ensino das disciplinas matemáticas na Universidade era realizado em várias escolas: Engenharia, Arquitetura, Ciências Econômicas e Faculdade de Filosofia, esta última a sede do curso de Matemática, que formava licenciados e bacharéis. A partir de 1965, reuniu-se a essas escolas outro lugar de ensino de Matemática na instituição - o Colégio Universitário 5 .

Um panorama da UFMG até os anos 1960 (Veiga et al., 1987) mostra uma instituição em que a administração central tinha um papel pequeno devido ao alto grau de autonomia das escolas, nas quais as congregações decidiam sobre os mais variados assuntos, dominando totalmente os cursos de graduação e extensão. Nas unidades, as principais responsáveis pelas decisões importantes, os catedráticos detinham o poder de direção e os professores eram, sobretudo, profissionais liberais que dedicavam parte de seu tempo à docência. Era comum um mesmo docente atuar em mais de uma escola, a exemplo dos que lecionavam Matemática na Escola de Engenharia e nas Faculdades de Filosofia e Ciências Econômicas. Convém destacar que a organização da carreira docente se baseava na cátedra, cujo titular tinha controle total sobre os professores assistentes, assim como nas congregações das escolas.

Nas décadas de 1940 e 1950, a Universidade contava com alguns pesquisadores em ciências biológicas e exatas, que, principalmente por esforços pessoais, conseguiam recursos para realizar seus trabalhos. Contudo, a pesquisa não era reconhecida como atividade essencial e a instituição não era dotada da organização necessária para acolhê-la. Até o início da década de 1960, a UFMG não tinha uma estrutura institucional que possibilitasse o funcionamento da pós-graduação de maneira sistemática. Nos poucos lugares em que ela existia, não estava estruturada em cursos regulares e os títulos eram concedidos mediante apresentação de dissertação ou tese diante de bancas compostas para isso.

Nesse cenário, a UMG/UFMG era uma confederação de escolas com autonomia quase total, e três delas - Direito, Medicina e Engenharia -, das quais se originou, até 1963, a maior parte dos reitores, eram as que tinham o peso maior nas decisões.

Desde 1964, a legislação federal, mediante diversos decretos, fez modificações quanto aos estudantes, ao corpo docente e à estrutura do ensino superior. Antes da reforma de 1968, as representações estudantis foram fortemente reprimidas pelos decretos-lei 4464/1964 e 228/1967. Criou-se a carreira do magistério universitário pela Lei 4881-A, de 1965; proibiuse a duplicação de meios para fins idênticos (Decreto-lei 53, de 1966); os departamentos foram definidos como unidades básicas de ensino superior (Decreto-lei 252, de 1967); extinguiram-se as cátedras (Lei 5539/1968). A Lei 5540/1968 reforçou pontos anteriormente

\footnotetext{
${ }^{5}$ O Colégio Universitário da UFMG foi criado em 1965 e oferecia apenas a terceira série do então ensino colegial, último ano da escola secundária da época. Constituía uma "experiência pedagógica que permitiria o amadurecimento do aluno, sua maior consciência da realidade nacional e regional, preparando-o para realizar o curso superior em melhores condições de desenvolvimento (intelectual, social, cultural)" (Collares, 1989, p. 172).
} 
estabelecidos, como a extinção das cátedras e a instituição dos departamentos como unidades básicas, mas também fez acréscimos às alterações anteriores. A criação dos ciclos básicos, a normatização dos colegiados para administração das atividades acadêmicas, o fortalecimento do poder central, as mudanças no vestibular, a regulamentação da representação estudantil e a institucionalização da pesquisa, entre outros, são componentes de destaque da reforma de 1968 (Brasil, 1968).

Na UFMG, no período 1964-1967, durante o reitorado de Aluísio Pimenta ${ }^{6}$, tinham sido implantadas iniciativas que desencadearam a reforma universitária antes do movimento do governo federal que culminou na Lei 5540/1968. Catedrático de duas faculdades, a de Farmácia e a de Filosofia, já em seu discurso de posse Pimenta propôs a reestruturação interna da Universidade, mediante a criação dos institutos centrais, que, em suas palavras, seriam "a mais eficiente arma contra o particularismo das escolas" (Resende \& Neves, 1998, p. 45). Os institutos centrais, segundo os moldes norte-americanos, deveriam ter seus prédios construídos no campus e abrigariam o ensino e a pesquisa básica de forma protegida do ambiente externo, enquanto as escolas profissionais, dispersas no tecido urbano, atenderiam as demandas mais imediatas da comunidade, do mercado de trabalho e das empresas. De acordo com Cunha (2007, p. 116), antes de sua escolha para reitor, Aluísio Pimenta havia visitado universidades nos Estados Unidos, "fonte inspiradora da modernização do ensino superior brasileiro", e, na volta, tinha conhecido a Universidade de Brasília, criada em 1961 e inaugurada em 1962, "sua versão nacional mais avançada.” Pimenta buscou seguir o modelo da UnB para a modernização da UFMG.

Conforme Veiga et al. (1987), o Estatuto da UFMG aprovado em 1963, no reitorado imediatamente anterior ao de Pimenta, previa a instalação dos Institutos Centrais de Física, Química, Matemática, Ciências Biológicas, Ciências Geológicas e Direito Público e Ciências Políticas. Na gestão de Pimenta, foram formadas comissões de professores para planejar as novas unidades, que teriam as seguintes funções: a) centralização de todas as disciplinas consideradas básicas, tanto as que vinham sendo ministradas nas escolas e faculdades profissionais quanto as dos cursos de graduação a serem desenvolvidos nos próprios institutos; b) realização das funções anteriormente desempenhadas pela Faculdade de Filosofia no nível da graduação; c) implementação do ensino de pós-graduação, vinculado às atividades de pesquisa, de forma a criar condições para a especialização e o aperfeiçoamento no âmbito da própria UFMG.

Depois de alguns meses de trabalho das comissões, coordenadas pelo Centro de Estudos Gerais, em fevereiro de 1966 foi decidido que seriam priorizados os Institutos

\footnotetext{
6 Aluísio Pimenta (1923-2016) nasceu em Peçanha (MG). Formou-se em 1945, no curso de Química Farmacêutica na Faculdade de Odontologia e Farmácia da Universidade de Minas Gerais (UMG), posteriormente denominada Universidade Federal de Minas Gerais (UFMG). Doutorou-se em Química Orgânica e Biológica na UMG em 1950. Foi professor catedrático da Faculdade de Farmácia e da Faculdade de Filosofia dessa universidade, na qual ingressou como docente em 1947 e se tornou reitor em 1964. Exerceu o reitorado da UFMG até 22 de fevereiro de 1967, quando foi aposentado compulsoriamente pela Junta Militar que exercia a Presidência da República. Em decorrência da Anistia, foi reintegrado à instituição em 1981 (Resende \& Neves, 1998).
} 
Centrais de Matemática, Física e Química. Esses foram, de fato, os únicos institutos centrais instalados durante a gestão de Aluísio Pimenta ${ }^{7}$. É fundamental sublinhar que as reformas propostas pelo reitor não eram igualmente aceitas pela comunidade universitária, que contava com alguns focos de adesão e outros de resistência às mudanças. Veiga et al. (1987) assinalam uma motivação política para a priorização conferida aos institutos centrais de ciências exatas. Seu projeto envolvia três departamentos anteriormente existentes na Faculdade de Filosofia (FAFI), os de Matemática, Física e Química, em que Aluísio Pimenta contava com aliados entre docentes de ciências humanas e jovens professores da área de exatas que tinham se qualificado para a pesquisa no exterior e não tinham possibilidade de desenvolver suas atividades. Esses últimos viam as reformas como oportunidades para realizarem suas pesquisas. Ao mesmo tempo, o projeto implicava profundas modificações na estrutura da Escola de Engenharia, que opunha forte resistência às mudanças.

Portanto, minar o poder dessa Escola, com o apoio praticamente total da FAFI, através da transferência de professores, equipamentos e recursos financeiros para os Institutos Centrais de Matemática, Física e Química era um ganho político significativo da reitoria e um trunfo para o plano de Reforma (Veiga et al., 1987, p. 26).

Nos anos de 1965 e 1966, foi aprovado o Estatuto da UFMG, que previa os três institutos centrais. Aluísio Pimenta pretendia ser conduzido a um segundo mandato, no qual daria continuidade às reformas, e seu nome integrou a lista tríplice da qual o governo federal escolheria o sucessor. Entretanto, com as mudanças que tinham se operado no quadro político nacional a partir do golpe militar de 1964, os grupos da Universidade que se opunham às inovações conseguiram se articular para garantir a escolha do nome do vice-reitor da gestão que acabava. Esse docente, professor Gerson de Britto Mello Boson ${ }^{8}$, da Faculdade de Direito, cujo nome também compunha a lista tríplice, foi rapidamente nomeado (Veiga et al., 1987). De acordo com essas autoras, que investigaram as atas das reuniões do Conselho Universitário durante a nova gestão, as escolas que se sentiam mais atingidas pela reforma passaram a criticar contundentemente a criação dos institutos centrais. Em particular, os docentes das escolas de Arquitetura e Engenharia manifestaram sua descrença "de que outro tipo de profissional pudesse ensinar as matérias básicas, principalmente a matemática, a seus estudantes" (Veiga et al., 1987, p. 30). Desse modo, esses professores resistiram à transferência de suas disciplinas para os institutos centrais de Ciências Exatas até 1969, quando foram obrigados a aceitá-la em decorrência da Lei 5540.

\footnotetext{
${ }^{7}$ Em sua exposição de motivos da prioridade para os três Institutos Centrais, o reitor enumerava três razões para a decisão: a importante potencial contribuição desses três setores para programas de desenvolvimento industrial e tecnológico, o fato de os três institutos abrangerem as mesmas escolas e faculdades, o que facilitaria a organização de cursos e programas, e o excepcional entrosamento entre as comissões desses institutos (Veiga et al., 1987).

${ }^{8}$ Gerson de Britto Mello Boson (1914- 2001) nasceu em Piracuruca, no Piauí, e se formou como bacharel em Direito pela Faculdade de Direito da UMG em 1944. Em 1952, tornou-se catedrático de Direito Internacional Público dessa Faculdade. Foi vice-reitor da UFMG no período 1964-1967, tendo assumido a reitoria em 22 de fevereiro de 1967 em virtude da aposentadoria compulsória de Aluísio Pimenta. Boson também foi aposentado compulsoriamente pela Junta Militar no decorrer do mandato de reitor, em 13 de outubro de 1969. Após a Anistia, foi reintegrado à UFMG em 1980 (Resende \& Neves, 1998).
} 
Em entrevista concedida em 1988, o ex-reitor Gerson Boson, ao ser indagado acerca dos desvios dos rumos da reestruturação da UFMG após a imposição da reforma de 1968 , enfatizou o papel central dos Institutos Centrais nessa reestruturação, e declarou que eles foram conservados pela reforma decretada pelo governo federal (Resende \& Neves, 1998). Os três Institutos Centrais funcionaram no campus da Universidade durante os anos letivos de 1967 e 1968 e localizamos alguns diários de classe identificados em suas capas como pertencentes ao Instituto Central de Matemática. Esses diários registram disciplinas ministradas anualmente a estudantes dos cursos de Matemática e Física por professores que atuavam na Escola de Engenharia e na Faculdade de Filosofia. O testemunho de Maria Suzana Balparda de Carvalho, aluna do bacharelado em Matemática no período 1965-1968, posteriormente docente do Departamento de Matemática do Instituto de Ciências Exatas, corrobora nossa percepção de que os cursos que passaram a funcionar no Instituto Central de Matemática, no campus universitário, eram apenas aqueles sediados anteriormente na Faculdade de Filosofia. Suzana relembrou a mudança do curso, a partir de seu terceiro ano como aluna, para a nova escola.

E nós viemos para cá; veio a Física, a Matemática e a Química. (...) Então eu tive aula aqui. Nós estávamos aqui.... Teoricamente as aulas de Matemática da Engenharia já eram responsabilidade do Instituto de Matemática, só que eles só vieram para cá para o campus vários anos depois, uns 4 anos depois, eu acho (Entrevista de Maria Suzana Balparda de Carvalho, 06/10/2017).

A experiência de manutenção dos três institutos de ciências exatas durou apenas dois anos. Ainda em 1968, eles se reuniram em uma única escola, o Instituto de Ciências Exatas (ICEx), e os docentes passaram a integrar os departamentos de Matemática, Física e Química. Conforme o relatório de gestão do reitor Marcello de Vasconcellos Coelho ${ }^{9}$, sucessor do reitor Gerson Boson ${ }^{10}$, antes da Lei 5540, em 28 de fevereiro de 1968, era aprovado o plano de reestruturação da UFMG, pelo qual os três institutos se agregariam para constituir a nova unidade, o ICEx (Resende \& Neves, 1998).

\footnotetext{
${ }^{9}$ Marcello de Vasconcellos Coelho (1930-2004) nasceu em João Pessoa, na Paraíba, e se formou em Medicina pela Universidade Federal de Pernambuco em 1954. Doutorou-se em Parasitologia pela UFMG em 1967. Foi reitor (1969-1973) e diretor (1975-1979) do Instituto de Ciências Biológicas da UFMG (Resende \& Neves, 1998). Disponível em https://www.ufmg.br/online/arquivos/000850.shtml. Acesso em 15 nov. 2021.

${ }^{10}$ De acordo com Veiga et al. (1987), a gestão de Boson foi marcada por idas e vindas em relação às reformas. Por um lado, o próprio reitor era contrário a elas, e muitos professores, acreditando na possibilidade de revertêlas, atuaram nesse sentido. Por outro lado, havia muitos professores favoráveis a uma modernização da Universidade, ligados ao reitor Pimenta, que se mobilizaram em favor das mudanças. Apesar do predomínio dos grupos conservadores na administração central da Universidade, a reforma iniciada por Pimenta foi institucionalizada. O reitorado de Boson também se caracterizou pelo aumento das pressões políticas externas, e sua aposentadoria compulsória, em 16 de outubro de 1969, pela Junta Militar que governava o Brasil, foi apenas um dos eventos repressivos que atingiram outros professores, alunos e funcionários da UFMG. Entre os professores da UFMG punidos pelo regime, esteve também o ex-reitor Aluísio Pimenta, aposentado compulsoriamente no mesmo dia que Boson. Marcello Coelho, ligado a pesquisadores da área de ciências biológicas da Universidade e professor da Faculdade de Farmácia, substituiu Boson a partir de 13 de dezembro de 1969, tendo encerrado seu mandato em 13 de dezembro de 1973 (Resende \& Neves, 1998).
} 


\section{O Departamento de Matemática: atribuições advindas da reforma universitária e movimentos iniciais}

O Departamento de Matemática foi constituído pela reunião de um número muito grande de professores, que antes pertenciam ao corpo docente de diferentes unidades da UFMG: Escola de Engenharia, Faculdade de Ciências Econômicas, Escola de Arquitetura, Faculdade de Farmácia, Faculdade de Filosofia e Colégio Universitário. Transferir-se para o ICEx, localizado no campus da Pampulha, naquela época considerado muito distante da região central de Belo Horizonte, não foi uma decisão aceita tranquilamente por todos os docentes. Um trecho da narrativa da professora Suzana evidencia esse aspecto de resistência. Ela mencionou como exemplo o professor Edmundo Menezes Dantas ${ }^{11}$, que era professor catedrático na Escola de Engenharia e, também, na época da mudança, o chefe do Departamento de Matemática da Faculdade de Filosofia.

O Dantas abandonou o Departamento. Ele era o chefe do Departamento de Matemática na FAFICH ${ }^{12}$. Quando era pra mudar pra cá, ele abandonou, foi quando o Edson ${ }^{13}$ pegou. Então é começar da estaca zero. Você tá vendo a história do Instituto de Matemática que virou Departamento. Esse Instituto de Matemática foi formado pela reunião dos departamentos de Matemática que tinham na FAFICH, na Ciências Econômicas, na Engenharia, em todo lugar tinha o seu departamento de Matemática com seu corpo docente. Alguns dos professores davam aula em dois desses lugares, mas o Instituto de Matemática, em 1967, foi formado com a aglutinação desses departamentos. Formalmente, porque várias pessoas não vieram pra cá. A Escola de Engenharia continuou a ter aulas de Matemática lá, a Ciências Econômicas também. Então, principalmente essas faculdades que eram mais fortes, elas continuaram tendo aula de Matemática lá. (Entrevista em 06/10/2017).

Nos primeiros anos do Departamento de Matemática do ICEx, como em outros departamentos surgidos a partir da Reforma, houve muita movimentação de docentes, que pediram transferência para outras unidades. Ademais, estavam inicialmente lotados no Departamento de Matemática professores que lecionavam disciplinas ligadas à Estatística e à

\footnotetext{
11 Edmundo Menezes Dantas (1904-2001) nasceu em Riachão do Dantas, em Sergipe. Formou-se em Engenharia Civil e de Minas na Escola de Minas de Ouro Preto em 1928. A partir de 1944, foi professor catedrático de Cálculo Infinitesimal e Vetorial na Escola de Engenharia e, desde 1950, de Geometria, na Faculdade de Filosofia da UMG, futura UFMG. Atuou também como diretor e professor da Fundação Mineira de Educação e Cultura (Fumec), em Belo Horizonte, no período 1969-1987. Escreveu livros para o ensino superior de Matemática, tais como Elementos de Equações Diferenciais e Elementos de Cálculo Vetorial (Faculdade de Filosofia, 1954).

${ }^{12}$ A professora usou a sigla que passou a designar a Faculdade de Filosofia e Ciências Humanas após a reforma de 1968. Em 1967, a unidade a que pertencia o professor Dantas ainda se chamava Faculdade de Filosofia, Ciências e Letras.

${ }^{13}$ Suzana se referiu ao professor Edson Durão Judice, o primeiro chefe do Departamento de Matemática do ICEx.
} 
Computação. O Departamento de Ciência da Computação e Estatística, criado em 1972 dentro do ICEx, acolheu esses docentes ${ }^{14}$.

Os primeiros anos foram, então, caracterizados, como em todos os novos departamentos originados da reforma de 1968, pela extinção das antigas cátedras; pelo trânsito de professores; pela implantação gradativa de um novo regime de trabalho dos docentes, a dedicação exclusiva; pelas grandes demandas de normatização das atividades. Cabe destacar, ainda, que como o colegiado do curso de Matemática só passou a existir no segundo semestre de 1969, as decisões iniciais relativas aos currículos e aos pedidos de estudantes desse curso couberam também ao âmbito do Departamento. Os julgamentos, deferimentos e indeferimentos eram, então, responsabilidade da Câmara, presidida pelo primeiro chefe do Departamento de Matemática, antes diretor do Instituto Central de Matemática, o professor Edson Durão Judice ${ }^{15}$, que permaneceu no cargo até 1972.

As atas das reuniões da Câmara Departamental ${ }^{16}$ constituem documentos relevantes para mapear os diversos encaminhamentos das questões envolvidas. Antes mesmo da constituição desse órgão, após eleição de seus membros, a ata de uma reunião geral dos professores do Departamento, realizada em 09/01/1969, registra a abordagem da responsabilidade pela Matemática na Universidade, que englobava, além dos cursos de Matemática, Física e Química sediados no ICEx, os cursos de diversas outras unidades, a exemplo da Escola de Engenharia, da Faculdade de Ciências Econômicas, da Escola de Arquitetura, da Faculdade de Medicina e da Faculdade de Farmácia. Na mesma reunião, focalizou-se o projeto para o curso de pós-graduação (mestrado) em Matemática na UFMG pela leitura de um memorial anteriormente encaminhado à Coordenação do Aperfeiçoamento de Pessoal de Nível Superior (CAPES), que foi aprovado unanimemente pelos presentes.

A pós-graduação, a capacitação e a carreira docentes, bem como o novo regime de trabalho, a dedicação exclusiva, que seria implantado na UFMG a partir de 1970, são aspectos inter-relacionados recorrentemente mencionados nas atas das reuniões da Câmara do Departamento de Matemática no período 1969-1973, precisamente aquele do reitorado do professor Marcello de Vasconcellos Coelho. Um trecho de seu relatório final de gestão, após enumerar pontos importantes de suas realizações, deixa clara a vinculação entre as atividades dos docentes, seu regime de trabalho e a capacitação via cursos de pós-graduação.

\footnotetext{
${ }^{14}$ Posteriormente, em 1976, nova reestruturação foi promovida com a criação do Departamento de Estatística do ICEx. O Instituto é constituído, atualmente, pelos cinco departamentos existentes a partir de então: Matemática, Física, Química, Ciência da Computação e Estatística.

15 Edson Durão Judice (1925-2018) nasceu em Belo Horizonte e se formou em Engenharia Civil pela Universidade de Minas Gerais (UMG) em 1948. Fez estudos no Instituto de Matemática Pura e Aplicada em 1953 e 1960. Tornou-se livre-docente da Faculdade de Ciências Econômicas (1955) e catedrático de Geometria Analítica e Projetiva da Escola de Engenharia (1962) da UMG. Foi diretor do Instituto Central de Matemática e primeiro chefe do Departamento de Matemática da UFMG. Escreveu livros para o ensino de Geometria Analítica, Álgebra Linear e Cálculo Diferencial e Integral. Disponível em http://lattes.cnpq.br/2976484496590401. Acesso em 14 nov. 2021.

${ }^{16}$ Usamos os dois primeiros livros dessas atas. O primeiro (UFMG, 1973) cobre o período de 08/01/1969 a 26/06//1973 e o segundo (UFMG, 1977) abrange de 26/06/1973 a 06/05/1977.
} 
Outra medida a exigir definição foi o estabelecimento, ainda que imperfeito, de critérios amplos e objetivos para avaliar a carga didática docente, necessária não só para caracterizar condições justificadoras de regime de trabalho especial, como para permitir avaliar a capacidade docente real da Universidade. Nessa tarefa, foi possível criar condições de estímulo para os docentes que se empenhassem em cursos de pósgraduação e em atividades de pesquisa, e reafirmar o primado do Departamento na Universidade (Resende \& Neves, 1998, p. 106).

A Lei 5540/1968, no capítulo dedicado ao corpo docente, estabelecia que, para o ingresso e as promoções na carreira, seriam considerados os títulos universitários. Além disso, havia os artigos 34 e 35, que prescreviam a extensão progressiva aos professores do regime de dedicação exclusiva ao ensino e à pesquisa e conferiam prioridade desse regime “às áreas de maior importância para a formação básica e profissional" (Lei 5540, de 28 de novembro de 1968 $)^{17}$. Pelo artigo 36, os programas de aperfeiçoamento dos docentes do ensino superior seriam estabelecidos pelas universidades, "dentro de uma política nacional e regional definida pelo Conselho Federal de Educação e promovida através da CAPES e do Conselho Nacional de Pesquisas" (Lei 5540, de 28 de novembro de 1968).

\section{Capacitação, carreira docente, pós-graduação e dedicação exclusiva nos primórdios do Departamento de Matemática}

A capacitação dos professores de Matemática da UFMG tinha sido tornada obrigatória para a carreira pela reforma de 1968, mas, antes mesmo da criação do Departamento de Matemática do ICEx, constatam-se indícios de iniciativas de capacitação de docentes da área. Assim, na Escola de Engenharia, por exemplo, o relato do professor Roberto de Maria Nunes Mendes, por nós entrevistado, incluiu a realização de cursos para professores dados por docentes da instituição que tinham ido, anteriormente, estudar nos Estados Unidos. Um deles, Eliseu Resende ${ }^{18}$, com título de doutor obtido na Universidade de Nova York, em 1963, lecionou Teoria da Medida e Equações Diferenciais Parciais e Roberto participou de um desses cursos.

No recém-criado Departamento de Matemática, em 1969, alguns professores que até então atuavam na Escola de Engenharia e na Faculdade de Filosofia estavam inseridos como estudantes em programas de pós-graduação. As atas das reuniões da Câmara, desde o primeiro ano, trazem registros com essas indicações. Assim, a primeira ata, de 13 de fevereiro, atesta o pedido de licença do professor Roberto de Maria Nunes Mendes, na época mestrando no Instituto de Matemática Pura e Aplicada (IMPA), no Rio de Janeiro, para realizar doutorado nos Estados Unidos. Contemplado com bolsa do então Conselho Nacional

\footnotetext{
${ }^{17}$ Disponível em https://www2.camara.leg.br/legin/fed/lei/1960-1969/lei-5540-28-novembro-1968-359201publicacaooriginal-1-pl.html. Acesso em 30 mar. 2021.

${ }^{18}$ Eliseu Resende (1929- 2011) nasceu em Oliveira (MG) e graduou-se em Engenharia Civil pela atual UFMG em 1954. Durante a Ditadura Militar, foi diretor do DNER (Departamento Nacional de Estradas de Rodagem) no período 1967-1974 e ministro dos Transportes de 1979 a 1982. Candidato derrotado ao governo de Minas Gerais, elegeu-se, posteriormente, deputado e senador pelo Partido da Frente Liberal (PFL). Disponível em https://www.fgv.br/cpdoc/acervo/dicionarios/verbete-biografico/eliseu-resende. Acesso em 15 nov. 2021.
} 
de Pesquisas (CNPq), Roberto, que teve seu pedido de licença aceito, cursou o doutorado na Universidade da Califórnia em San Diego, no período 1969-1973 ${ }^{19}$.

Atas de 1969 e 1970 mostram pedidos de continuidade da licença do professor José Pedro da Fonseca, antes docente da Faculdade de Filosofia, para doutorado no Massachussets Institute of Technology (MIT), também nos Estados Unidos, em virtude da prorrogação de sua bolsa pela Fundação Rockfeller ${ }^{20}$. Ainda em atas de 1970, verificamos, pelos registros do pedido de renovação de licença e do envio de relatórios de atividades, que o professor Waldir Resende Penedo, também lotado anteriormente na Faculdade de Filosofia, estava afastado da UFMG para mestrado no ITA-Instituto Tecnológico da Aeronáutica ${ }^{21}$.

Logo em seu início, portanto, o Departamento tinha, entre seus professores licenciados para capacitação, pelo menos dois doutorandos nos Estados Unidos e um mestrando no Brasil. Havia ainda, no quadro docente, professores portadores do título de doutor. O professor Edson Durão Judice tinha o título de doutor por ter sido, desde 1962, catedrático de Geometria Analítica e Projetiva na Escola de Engenharia, após aprovação em concurso com defesa de tese elaborada a partir de estudos realizados com bolsa do CNPq no IMPA $^{22}$. No corpo docente, figurava também Aristides Camargos Barreto (1935-2016), antes professor da Escola de Engenharia, um dos primeiros três doutores formados pelo IMPA, em 1964, orientados por Maurício Matos Peixoto ${ }^{23}$.

Roberto Mendes, em sua entrevista, falou de estudos que realizou, ainda como professor da Escola de Engenharia, com Aristides.

Agora, eu aprendi mais mesmo foi com o Aristides. Porque o Aristides quando voltou ${ }^{24}$, ele dava aula sábado à tarde para a gente. Aí ele deu Álgebra Linear, Espaços Métricos, Teoria de Grupos. Eu lembro que fui eu que expus Teoria de Grupos, um livro grandão assim, publicado pela, lá pelo Rio, lá por Fortaleza, eu acho. Era um livro grande

\footnotetext{
${ }^{19}$ Conforme o currículo Lattes do professor, disponível em http://lattes.cnpq.br/6719952816209548. Acesso em 14 abr. 2021.

${ }^{20}$ De acordo com Motta (2014), desde os anos 1920 a Fundação Rockfeller financiava projetos para equipar laboratórios ligados a instituições universitárias no Brasil. Em 1970, um relatório encomendado pela Usaid (United States Agency for International Development) identificou 128 projetos de financiamento externo da educação brasileira, e a maioria se destinava ao pagamento de bolsistas no exterior. As principais agências eram a OEA (Organização dos Estados Americanos) e a ONU (Organização das Nações Unidas), através do Banco Mundial e do BID (Banco Interamericano de Desenvolvimento). As doações da Fundação Rockfeller, na época, montavam a 227 mil dólares, ao passo que as da Fundação Ford eram de 16,5 milhões de dólares

21 O ITA, criado em 1950, era uma instituição de ensino superior organizada modernamente com estrutura acadêmica departamental, com professores que trabalhavam em tempo integral, de forma a possibilitar a pesquisa (Motta, 2014). Seus cursos de pós-graduação começaram em 1961 e os primeiros trabalhos foram defendidos em Física e Engenharia Eletrônica no ano de 1963. Conforme http://www.ita.br/historiacursos. Último acesso em 15 abr. 2021.

${ }^{22}$ Conforme o currículo Lattes do docente, disponível em http://lattes.cnpq.br/2976484496590401. Último acesso em 14 abr. 2021.

${ }^{23}$ A tese de Aristides se intitula "Estabilidade Estrutural das Equações Diferenciais da Forma X $=\mathrm{S}(\mathrm{X}, \mathrm{X})$ ". Disponível em https://impa.br/pesquisa/lattes/. Acesso em 08 abr. 2021.

${ }^{24} \mathrm{O}$ professor referia-se à volta de Aristides à UFMG após a realização de seu doutorado no IMPA.
} 
assim, sobre teoria de grupos. Eu expus tudo lá, toda a teoria de grupos. Então, era ele que incentivava a gente (Entrevista em 20/09/2017).

Aristides Camargos Barreto foi professor do Instituto Central de Matemática, onde lecionou, em 1967, Geometria Diferencial e Topologia Geral, conforme informam os diários de classe dessas disciplinas. Contudo, ele não chegou a participar do Departamento de Matemática do ICEx. Desde 1969, passou a atuar como professor visitante na Pontifícia Universidade Católica do Rio de Janeiro (PUC-Rio). A ata de uma reunião da Câmara de abril de 1970 menciona uma carta assinada pelo reitor daquela instituição que argumentava em favor da necessidade de Aristides lá permanecer durante todo o ano letivo, para continuar o trabalho que vinha desenvolvendo no programa de pós-graduação em Matemática. De acordo com a ata, apesar de a ocasião ser inconveniente para o ICEX, a solicitação foi atendida, mas foi registrado que esse atendimento implicava o compromisso de retorno do docente ao Departamento de Matemática em $1^{\circ}$ de março de 1971. Esse registro parece refletir o incômodo e o descontentamento dos membros da Câmara do Departamento de Matemática com o deferimento do pedido, tendo em vista que o projeto de Mestrado em Matemática, então em andamento na UFMG, precisava de doutores para ser efetivado, e certamente contava com a participação do professor Aristides $^{25}$. Aristides acabou não retornando para a UFMG; trabalhou na PUC-Rio por 30 anos, tendo se aposentado em 1999.

A carreira universitária demandava a capacitação dos professores do Departamento de Matemática, o que significava, sobretudo, que eles obtivessem o título de mestre o mais rapidamente possível. Ter pelo menos essa titulação era importante para ascender na carreira e ter acesso a melhores condições de trabalho, além de representar a possibilidade de iniciação na atividade de pesquisa, claramente estabelecida pela reforma de $1968^{26}$. A leitura das atas das reuniões da Câmara Departamental no período 1969-1977 mostra a presença de diversos pedidos de licença, de redução de carga didática ou de permissões de afastamento do ICEx por curtos períodos. São pedidos relacionados a tentativas, feitas pelos professores, de cursar o mestrado em várias áreas. De 1969 até 1977, localizamos registros de busca de docentes pelo mestrado em Administração de Empresas, na própria UFMG ou na Fundação João Pinheiro, em Belo Horizonte; Informática, na PUC-Rio; Estatística, no IMPA; Economia, na UFMG; Ensino de Matemática, na Unicamp. Esses pedidos foram, em alguns casos, atendidos e, em outros, recusados ou apenas parcialmente atendidos. Os professores que desejavam fazer mestrado em Informática ou Estatística tiveram seus pedidos de licença

\footnotetext{
${ }^{25}$ Um ano depois, em abril de 1971, outra ata registra a prorrogação da licença sem vencimentos do professor para prosseguir orientando estudantes de mestrado na PUC-Rio, novamente a pedido da própria instituição, por mais um ano. Em 1972, ocorreu nova renovação, por mais um ano, da licença solicitada pelo docente. A ata dessa reunião de 5 de maio apresenta a razão para o deferimento do pedido: a colaboração que essa Universidade vinha prestando à UFMG por meio de seu Departamento de Informática.

${ }^{26}$ A reforma instituiu a indissociabilidade entre ensino e pesquisa, estabelecendo no primeiro artigo do capítulo intitulado "Do Ensino Superior": "O ensino superior tem por objetivo a pesquisa, o desenvolvimento das ciências, letras e artes e a formação de profissionais de nível universitário". Disponível em https://www2.camara.leg.br/legin/fed/lei/1960-1969/lei-5540-28-novembro-1968-359201-publicacaooriginal-1pl.html. Acesso em 14 abr. 2021.
} 
aprovados, mas posteriormente, com a criação dos departamentos de Ciência da Computação e Estatística no ICEx, para lá se transferiram.

Também se evidenciaram esforços de vários professores com vistas a preparar-se para o mestrado em Matemática nos pedidos de financiamento para ir ao Colóquio Brasileiro de Matemática ou de licença para receber bolsa para cursos de verão no IMPA. Houve várias referências de professores entrevistados a cursos ou seminários oferecidos de maneira informal na própria UFMG, cujo objetivo era ampliar os conhecimentos dos docentes de modo que pudessem, posteriormente, acompanhar disciplinas do mestrado. A ata de uma reunião da Câmara Departamental de 1969 noticia que estava sendo estudado um convênio entre o Banco Nacional de Desenvolvimento Econômico (Funtec) ${ }^{27}$ e o IMPA a fim de conceder bolsas ao pessoal do Departamento de Matemática para obtenção de mestrado naquela instituição nos próximos anos ${ }^{28}$.

Outro tipo de registro nas atas dos anos iniciais atesta investimentos feitos no âmbito do Instituto de Ciências Exatas para a pesquisa e a pós-graduação: a compra de livros e periódicos científicos, parte deles destinados ao Departamento de Matemática. Em junho de 1970, o diretor do ICEx assinou uma portaria criando comissões para tratar de assuntos relativos à pós-graduação em Matemática, Física e Química.

Um aspecto essencial à reforma universitária era o relacionado ao regime de trabalho dos professores. Desde 1965, a lei 4881-A previra o regime de dedicação exclusiva (DE) para os docentes do sistema federal, que existia antes somente no ITA e na Universidade de São Paulo (USP). A implantação desse regime "estava no cerne das propostas de modernização, pois daria aos professores condições efetivas de pesquisa, com redução da carga didática" (Motta, 2014, p. 245) Todavia, essa nova legislação teve pouco impacto imediato, pela falta de recursos das universidades nessa época. No final de 1968, ficou estabelecido que o regime de DE seria regulamentado em futuro decreto; a implantação seria paulatina e sujeita à análise do plano de trabalho do professor interessado. Somente em 1970, houve a regulamentação definitiva, com o estabelecimento de quatro faixas de trabalho: 12 horas, 24 horas, 40 horas e 40 horas com DE. Ela significou um reajuste expressivo nos vencimentos dos professores, o que tornou a carreira bem atrativa para os que conseguiam obter a dedicação exclusiva (Motta, 2014).

No Departamento de Matemática, os nomes dos primeiros contemplados com o regime de DE estão registrados em ata da reunião da Câmara de 24 de abril de 1970. Entre esses docentes, estavam alguns que, posteriormente, se transferiram para outros

\footnotetext{
${ }^{27}$ De acordo com Motta (2014), em maio de 1964 foi criado o Fundo de Desenvolvimento Técnico e Científico (Funtec), vinculado ao BNDE. Logo de início, o Funtec apoiou, nos meios acadêmicos, a Coppe (Coordenação dos Programas de Pós-Graduação em Engenharia), no Rio de Janeiro. Em seguida, o Funtec passou a financiar outros grupos de pesquisa e pós-graduação. Em 1969, foi transformado no FNDCT (Fundo Nacional de Desenvolvimento Científico e Tecnológico), também controlado e gerido pelo BNDE.

${ }^{28}$ Alguns docentes conseguiram, ao longo do período que focalizamos, obter licença para o mestrado naquela instituição e lá o concluíram; outros iniciaram o curso no IMPA, mas acabaram por terminá-lo no Mestrado em Matemática da própria UFMG.
} 
departamentos, como o de Ciência da Computação. Faziam parte dessa primeira leva o chefe do departamento, cinco docentes posteriormente transferidos e quatro que permaneceram na Matemática. Dentre esses, tem destaque a professora Maria Suzana Balparda de Carvalho, que tinha ingressado na UFMG em 1969; era, assim, uma docente recente, contratada desde o início para o Instituto de Ciências Exatas. Antes mesmo de haver o mestrado em Matemática na UFMG, conforme seu relato, Suzana já se preparava para esse nível da pós-graduação, tendo cursado disciplinas isoladas na própria UFMG e posteriormente no IMPA ${ }^{29}$.

No âmbito federal, um órgão do Ministério da Educação, a Comcretide (Comissão Coordenadora do Regime de Tempo Integral e Dedicação Exclusiva), definia o montante destinado à integração dos docentes ao regime de tempo integral e cada universidade, mediante a Copertide (Comissão Permanente do Regime de Tempo Integral e Dedicação Exclusiva), estabelecia as áreas e os professores a serem contemplados com o regime. De início, apenas cerca de $20 \%$ dos professores foram incluídos, o que gerou disputas e ciúme no estabelecimento de prioridades e, também, desencanto, por alguns docentes terem entendido que a DE seria oferecida imediatamente a todos (Motta, 2014).

À medida que se passavam os primeiros anos, foram concedidas vagas docentes ao Departamento de Matemática, tendo sido realizados concursos para os níveis de auxiliar de ensino, assistente e adjunto em 1973, para provimento das muitas demandas didáticas de diversos cursos. Gradualmente, foi crescendo o número de docentes em dedicação exclusiva, com incentivos para os que se envolviam, como alunos ou professores, na pós-graduação em Matemática, com destaque para aquela que se estabeleceria no próprio Departamento. Entretanto, é possível perceber, na leitura das atas das reuniões da Câmara, que nem todos os interessados conseguiam imediatamente o regime de DE. Nos anos de 1974 e 1975, ainda havia disputas para ocupar vagas desse regime originadas da desistência de seus ocupantes iniciais. As indicações dos novos ocupantes deveriam ser feitas em eleição pelos membros da Câmara e, em maio de 1975, dois desses membros abstiveram-se de indicar nomes e de votar, lamentando a política global da Universidade, que não proporcionava as mesmas condições e oportunidades àqueles que queriam se capacitar, dificultando que alguns pudessem prosseguir seus estudos, dedicando-se ao mestrado.

Os trabalhos desenvolvidos para a proposição, à administração central da Universidade, de um projeto de mestrado sediado no Departamento de Matemática levaram à aprovação desse curso no Conselho de Pós-Graduação da UFMG, em sessão realizada em 19 de outubro de 1971, conforme consta em comunicação do referido Conselho apresentada na reunião da Câmara do Departamento de Matemática de 12 de novembro do mesmo ano. A ata da reunião registra que o início do curso de Mestrado em Matemática havia sido aprovado, de acordo com projeto elaborado pelo Departamento de Matemática.

\footnotetext{
${ }^{29}$ Em sua entrevista, a professora contou ter se afastado do Departamento em 1971 para estudar no IMPA, no Rio de Janeiro. Posteriormente, realizou seus estudos de mestrado na Inglaterra, na Universidade de Warwick, finalizados em 1973. Na mesma universidade, esteve novamente, de 1981 a 1983, e concluiu o doutorado.
} 


\section{O Mestrado em Matemática da UFMG}

Ao ser aprovado, em 1971, o Mestrado em Matemática já tinha atravessado diversas etapas desde a constituição do Departamento. Com efeito, o projeto desse curso foi mencionado na primeira reunião dos professores, no início de 1969, como comentamos. As entrevistas de alguns professores que participaram dos primeiros momentos do curso nos possibilitam perceber que a capacitação docente, que havia começado na época em que os que lecionavam Matemática na UFMG estavam alocados, sobretudo, na Escola de Engenharia e na Faculdade de Filosofia, mediante estudos desenvolvidos localmente ou em outras instituições, foi um marco importante na trilha para a existência da pós-graduação stricto sensu em Belo Horizonte. O professor Roberto Mendes relatou que, ao voltar do IMPA após o término do mestrado, em março de 1969, enquanto esperava a concessão da bolsa para o doutorado nos Estados Unidos, lecionou a disciplina Introdução à Análise, informalmente, para alguns colegas do Departamento de Matemática. Na mesma época, o professor Edson Durão Judice ministrou Álgebra Linear. Roberto comentou que o início do Mestrado da UFMG pode ser situado nesse momento, logo após seu regresso do Rio de Janeiro.

Minha exposição foi no comecinho de março. Aí voltei para Belo Horizonte, ainda dei aula nesse semestre todo aí, primeiro semestre de 1969. Aí eu dei aula, eu dei um curso de Introdução à Análise. Foi o começo do mestrado aqui. Dei aula para os professores: Alvarenga, Castilho, Suzana, Wellington, a mulher do Wellington...Não havia diário de classe, era informal. O Edson deu Álgebra Linear pelo livro do Lang e eu dei Análise pelo livro do Bartle $e^{30}$. Isso é o embrião da pós-graduação. Até o Wellington fez. (Entrevista em 20/09/2017).

Dos nomes mencionados, Alberto de Alvarenga Cunha, Luís Flávio de Castilho e Maria Suzana Balparda de Carvalho, nossa entrevistada, eram docentes do Departamento. Suzana, em sua entrevista, lembrou-se das aulas referidas pelo professor Roberto: $O$ Roberto Mendes foi meu professor, não na graduação, mas deu aula para a gente, era uma disciplina mesmo, mas sem nenhuma formalização (Entrevista em 06/10/2017).

Castilho e Alvarenga eram formados em Engenharia na UFMG e provavelmente não tinham tido oportunidade de cursar, na graduação, as disciplinas citadas por Roberto. Wellington Celso de Melo (1946-2016) ${ }^{31}$ era, na época, aluno do curso de Engenharia

\footnotetext{
${ }^{30} \mathrm{O}$ entrevistado se referia aos livros The elements of real analysis, de Robert Gardner Bartle (1927-2003), publicado originalmente em 1964 pela John Wiley \& Sons, de Nova York, e Linear Algebra, de Serge Lang (1927-2005), publicado pela primeira vez em 1966 pela Addison-Wesley. Disponível em https://www.nytimes.com/2003/11/03/us/robert-g-bartle-75-mathematician-and-author.html https://mathshistory.st-andrews.ac.uk/Biographies/Lang/. Acesso em 16 nov. 2021.

31 Wellington de Melo cursou o doutorado no IMPA no período 1970-1972, orientado por Jacob Palis, com bolsa do CNPq. Também com apoio do CNPq, fez pós-doutorado em Berkeley, nos Estados Unidos, e em Warwick, na Inglaterra, de 1972 a 1974. Tornou-se pesquisador da área de sistemas dinâmicos no IMPA e foi membro titular da Academia Brasileira de Ciências e orientador de Arthur Ávila, agraciado com a Medalha Fields. Disponível em http://w3.impa.br/ demelo/. Acesso em 27 abr. 2021.
} 
Elétrica da UFMG. A professora Suzana, formada na UFMG em 1968, também se lembrou dessa época.

No início do ICEx, não havia pós-graduação em Matemática, mas havia a oferta de algumas disciplinas isoladas lecionadas pelos professores Roberto Mendes, Pedro Mendes e, de vez em quando, por algum professor visitante. Foi assim que começou a se estruturar o Mestrado, o que foi de grande importância para o departamento. (Entrevista em 06/10/2017).

Nessa fala, aparece o nome do professor Pedro Mendes, que teve grande participação na implantação do Mestrado em Matemática na UFMG e nos concedeu um depoimento escrito. Pedro contou que concluiu o Bacharelado em Matemática na UFMG em 1967, tendo começado os estudos na Faculdade de Filosofia e cursado o último ano no Instituto Central de Matemática, já no campus da Universidade. Posteriormente, fez mestrado no ITA, em São José dos Campos, no período 1968-1969. Em meados de 1969, Pedro transferiu-se para o Rio de Janeiro, para lecionar no Departamento de Matemática da PUC-Rio. Na época em que era bacharelando em Matemática, havia conhecido e feito amizade com Wellington de Melo, que estudava Engenharia Elétrica na Escola de Engenharia. No Rio, Pedro reencontrou-se e tornou-se colega de doutorado de Wellington, que era, então, orientado por Jacob Palis no IMPA. Esse pesquisador foi também o orientador de Pedro, que concluiu o curso no final de 1972 e, em janeiro de 1973, ingressou como docente no Departamento de Matemática da UFMG. O professor assim narrou sua participação na criação do Mestrado em Matemática:

O Wellington era monitor na Escola de Engenharia da UFMG e era muito amigo de seus professores Alvarenga, José Valério, Castilho, etc. Eu fui aluno do Prof. Castilho no Bacharelado. Surgiu nas conversas minhas com o Wellington a ideia de montar um curso de Mestrado em Matemática na UFMG, para dar oportunidade de aperfeiçoamento para esses professores, que certamente seriam capazes de fazer um bom Mestrado em Matemática. Isso nos motivou a realizar um projeto para esse curso. Organizamos um programa que começava com disciplinas de final de Bacharelado (Introdução à Análise, Introdução à Álgebra Linear, ...) chegando a disciplinas básicas de Mestrado, como Análise de Várias Variáveis, Topologia Geral, Geometria Diferencial, Álgebra, etc.

Procuramos o Diretor do ICEx, Prof. Francisco de Assis Magalhães Gomes ${ }^{32}$, no início de 1970, para pedir apoio ao nosso projeto. Fomos muito bem atendidos. Nós e colegas do IMPA nos organizamos e iniciamos a ofertar as disciplinas iniciais. Vínhamos do Rio regularmente para lecionarmos essas disciplinas. No final de 1972 concluí o Doutorado no IMPA e decidi mudar para Belo Horizonte para coordenar o curso mais de perto (Depoimento enviado por email aos autores em 09/04/2021).

\footnotetext{
${ }^{32}$ Francisco de Assis Magalhães Gomes (1906-1990) nasceu em Ouro Preto (MG) e graduou-se em Engenharia Civil e de Minas pela Escola de Minas dessa cidade. Concursado em 1938, foi catedrático de Física Geral e Experimental nessa Escola e de Física Geral na Escola de Engenharia da UMG, futura UFMG. Atuou também como catedrático de Física Teórica e Superior da Faculdade de Filosofia da UMG, futura UFMG. Foi um dos organizadores e o primeiro diretor do Instituto de Ciências Exatas (ICEx) da UFMG (Leão, 2002).
} 
As palavras do professor Pedro chamaram a atenção para o seu envolvimento e o de Wellington na implementação do projeto de pós-graduação. Pedro relembrou que 1973, ano em que ingressou como docente na UFMG, marcou o retorno ao Departamento dos professores José Pedro da Fonseca e Roberto de Maria Nunes Mendes, após a conclusão de seus doutorados no exterior, que era extremamente importante para que o Mestrado de fato passasse a existir.

Como em nosso trabalho as entrevistas têm papel de destaque, cabe-nos tecer uma breve consideração em relação aos testemunhos. Para o narrador, é difícil abordar "a multiplicidade de identidades e referências que se criam no espaço entre o vivido, o lembrado e o narrado" (Silva, 2012, p. 51-52).

A narrativa, condicionada por determinantes interiores e exteriores, individuais e coletivos, quer pelos temas que levanta ou omite, quer pelas referências nas quais se espelha, estabelece uma nova relação com a verdade, não pela factualidade, mas pelo seu significado (Silva, 2012, p. 54).

Nessa perspectiva, a partir da fala do entrevistado ou da entrevistada, é necessário apreender não apenas o que ele ou ela fez, "mas o que queria fazer, o que acreditava estar fazendo e o que agora pensa que fez" (Garnica, 2010, p. 37). Como Alberti (2006), acreditamos que é um equívoco pensar na entrevista como "a história". Ela é, para nós, apenas uma fonte que, como todas as fontes, precisa ser interpretada e analisada. Assim, os relatos passam a ser fontes históricas somente quando são problematizados.

É necessário, também, ponderar sobre os documentos escritos utilizados. As atas das reuniões da Câmara do Departamento de Matemática, principal material escrito por nós utilizado, não foram produzidas para futuras pesquisas históricas, mas para atender a necessidades específicas da época, a saber, para registrar o que se discutia e era decidido naquele órgão de modo a cumprir as normas da Universidade e evidenciar a transparência das ações e decisões. Verificamos que esses registros, no período investigado, eram muito cuidadosos e detalhados, e é relevante informar que as atas consultadas foram escritas à mão e redigidas por professores do Departamento, membros da Câmara que assumiam voluntariamente essa tarefa. Cremos que não havia funcionários disponíveis para secretariar as reuniões, o que também parece ser uma situação comum nos primeiros tempos pósreforma na UFMG. Os documentos escritos, como os testemunhos, não são neutros: trazem as marcas do tempo e dos autores; certamente, características de alguns professores, cuidadosos e caprichosos no estilo e na caligrafia, estão agregadas às atas que subsidiaram nossa pesquisa, mesmo que documentos desse tipo portem restrições de redação por sua própria natureza. Como qualquer documento escrito, não são a verdade, mas aquilo que se concordou deixar registrado, nesse caso para o cumprimento de uma tarefa exigida no âmbito universitário.

$\mathrm{Na}$ narrativa do professor Pedro Mendes, pode-se notar a proeminência do papel desempenhado pelo IMPA na criação do Mestrado de Belo Horizonte. A proximidade das relações entre IMPA e Departamento de Matemática da UFMG se manifesta em atividades promovidas por esse Instituto, referidas anteriormente, para as quais os professores do 
Departamento solicitavam licença ou financiamento. Ademais, houve docentes que fizeram mestrado no IMPA antes da criação desse curso na UFMG e, também, aqueles que, mesmo depois de iniciada a pós-graduação na UFMG, ingressaram nesse mestrado externo com licença do Departamento. Evidenciaram-se, nas atas consultadas e nos depoimentos dos professores Roberto, Pedro e Suzana, as fortes interações do Departamento de Matemática com o IMPA, seu principal interlocutor externo para a capacitação dos docentes.

Os testemunhos de Suzana e Roberto convergem no que diz respeito à grande participação de Pedro Mendes no início do Mestrado em Matemática. Roberto relatou que não o conhecia e que, quando voltou do doutorado, em 1973, encontrou-o no Departamento, já orientando, em fase de conclusão, as pesquisas de mestrado dos professores Alberto Alvarenga Cunha, José Valério da Silva e Luís Flávio de Castilho, os antigos docentes da Escola de Engenharia mencionados no depoimento de Pedro. Além deles, Pedro orientava Adairto Gonçalves dos Anjos, professor do Departamento desde 1970. Esses professores foram exatamente os quatro primeiros alunos concluintes do Mestrado em Matemática da $\mathrm{UFMG}^{33}$.

As atas das reuniões da Câmara Departamental e os testemunhos orais ou escritos de participantes dos primeiros momentos da pós-graduação em Matemática possibilitam compreender a importância das ações de muitos professores no sentido da implantação do Mestrado na UFMG. Para o sucesso desse empreendimento, que, ao mesmo tempo concretizava, na Universidade, o elemento básico da reforma universitária representado pela pós-graduação e pela pesquisa e significava a oportunidade real de capacitação dos professores, avaliamos que houve algumas ações anteriores e outras imediatamente posteriores à aprovação do curso. Assim, percebemos a relevância da busca de capacitação pelos docentes e das atividades de preparação desses professores para a pós-graduação nos momentos anteriores e nos tempos iniciais do Departamento de Matemática. Foram, ainda, essenciais os esforços para ministrar disciplinas e orientar pesquisas nos primeiros anos de funcionamento efetivo da pós-graduação. Tendo se iniciado na UFMG em 1972, no ano de 1977, marco final abrangido por nossa pesquisa, o Mestrado já contava com 13 dissertações aprovadas, todas elas produzidas e orientadas por professores do Departamento. Além dos quatro primeiros mestres já citados, três dos quais docentes anteriores à existência do Instituto de Ciências Exatas, nove outros professores e professoras mais jovens, ingressantes no quadro da UFMG após a reforma universitária, tinham obtido o título. Das 13 dissertações, nove foram orientadas pelo professor Pedro Mendes, duas pelo professor Roberto Mendes e duas pelo professor Mu-Chou-Liu, contratado em 1976. Na década seguinte, a maior parte dos mestres formados na UFMG continuou a ser constituída por docentes do Departamento. Conforme lembrou a professora Suzana, muitos dos professores mais novos eram recém-formados, e o Mestrado, no início, foi quase que dirigido para eles. Desse modo, a pós-graduação implantada em 1972 permitiu capacitar, sobretudo, os

33 Informações verificadas no site do Programa de Pós-Graduação em Matemática da UFMG: Alvarenga, Valério e Adairto defenderam seus trabalhos em 1974 e Castilho o fez em 1975. Disponível em http://www.mat.ufmg.br/posgrad/dissertacoes-de-mestrado/. Acesso em 05 mai. 2021. 
professores da própria UFMG. Para que esse resultado fosse alcançado, as políticas internas ao Departamento foram primordiais. De fato, as atas das reuniões da Câmara documentam que foram instituídos estímulos para os professores cursarem o Mestrado em Matemática, que são explícitos nas normas estabelecidas em 1974 para a concessão de licenças ou de redução da carga didática. A partir desse momento, a concessão ou não ficou condicionada à disponibilidade de professores para cumprimento dos numerosos encargos didáticos de responsabilidade do Departamento, estabelecendo-se prioridade para os interessados na pósgraduação em Matemática, especialmente em nível de doutorado. Salvo excepcionalidades, não haveria licença para cursar o mestrado fora do Departamento. Pedidos de redução de carga didática ou de licença seriam examinados à luz do desempenho dos docentes como estudantes de pós-graduação em Matemática e analisados mediante seus relatórios de atividades. A realização do mestrado em Matemática pelos docentes foi um elemento decisivo, também, na avaliação dos pedidos de dedicação exclusiva, quando não havia vagas para todos os professores nesse regime. Instituiu-se, inclusive, votação secreta pelos membros da Câmara para o julgamento das solicitações. Eventuais tentativas de docentes conseguirem licença ou redução de carga com a justificativa de realização de pós-graduação em outras áreas foram desincentivadas pelas diretrizes e medidas adotadas na Câmara do Departamento de Matemática.

\section{Para concluir}

Logo após a reforma universitária, estruturar os departamentos significava modernizar as universidades, com a criação das condições para implantar e desenvolver a pós-graduação. Para o ex-reitor da UFMG (1969-1973) Marcello Coelho, a pós-graduação só foi possível porque foram formados departamentos, e a pós-graduação era "o sistema formal de preparação de professores de alto nível para o país” (Resende \& Neves, 1998, p. 120).

A estreita vinculação entre a estruturação do Departamento de Matemática do ICEx e a criação e o florescimento do Mestrado em Matemática da UFMG são atestados nos livros de atas das reuniões da Câmara Departamental. Esses documentos não são o espelho da "verdade", mas sua leitura, aliada aos relatos dos professores, possibilitou-nos compreender as relações entre a composição, a capacitação e o regime de trabalho do corpo docente e seu engajamento na pós-graduação em Matemática.

Em 1977, o Departamento tinha renovado mais de metade de seu corpo docente original, o Mestrado contava com 13 dissertações defendidas e alguns egressos do curso haviam obtido licenças e bolsas para doutorado no exterior. O Mestrado repercutiu muito na capacitação dos professores, contemplando tanto aqueles de antes de 1969 quanto os ingressantes posteriores com a oportunidade de aperfeiçoamento na própria UFMG.

Percebemos que o Mestrado em Matemática resultou de muitos esforços e, fortemente marcado por uma instituição externa, o IMPA, alcançou sucesso, em grande parte, pelas políticas de estímulo adotadas pela direção do Departamento em seus primeiros anos. Ao mesmo tempo, houve desestímulo a outros tipos de capacitação docente. As políticas internas 
e os investimentos na capacitação em Matemática teriam repercussões em outras frentes da atuação do Departamento, em particular nas ações ligadas à formação de professores no curso de Licenciatura. Esse é um tema que pretendemos explorar em futuras investigações.

\section{Agradecimentos:}

Agradecemos à professora Rioco Kamei Barreto pelas informações sobre Aristides Camargos Barreto, seu esposo, e à professora Maria Sylvia Silva Dantas pelas informações sobre seu pai, Edmundo Menezes Dantas. Agradecemos ainda aos professores Maria Suzana Balparda de Carvalho, Pedro Mendes e Roberto de Maria Nunes Mendes por seus depoimentos.

\section{Referências}

Alberti, V. (2006). Fontes Orais: Histórias dentro da História. In C. B. Pinsky (org.), Fontes Históricas (pp. 155-202). São Paulo: Contexto.

Alves, M. F. \& Oliveira, J. F. (2014). Pós-Graduação no Brasil: do regime militar aos dias atuais. Revista Brasileira de Política e Administração da Educação, 30 (2), 351-376. https://doi.org/10.21573/vol30n22014.53680.

Bacellar, C. (2010). Uso e mau uso dos arquivos. In C. B. Pinsky (Org.), Fontes históricas (pp. 23-79). São Paulo: Contexto.

Brasil (1968). Lei $n^{\circ} 5.540$, de 28 de novembro de 1968. Fixa normas de organização e funcionamento do ensino superior e sua articulação com a escola média, e dá outras providências. Diário Oficial da União.

Collares, M. I. (1989). Colégio de Aplicação da Faculdade de Filosofia de Minas Gerais: a trajetória de uma escola de ensino médio no contexto universitário. Dissertação de Mestrado em Educação. Belo Horizonte: Universidade Federal de Minas Gerais.

Cunha, L. A. (2007). A universidade reformanda: o golpe de 1964 e a modernização do ensino superior. São Paulo: Editora Unesp.

Cunha, L. A. (2003). Ensino superior e universidade no Brasil. In E. M. Lopes, L. M. Faria Filho, \& C. G. Veiga (Orgs.), 500 anos de Educação no Brasil (pp. 151-204). 3 ed. Belo Horizonte: Autêntica.

Faculdade de Filosofia da Universidade de Minas Gerais (1954). Anuário da Faculdade de Filosofia da Universidade Federal de Minas Gerais: 1939-1953. Belo Horizonte: Gráfica Santa Maria.

Garnica, A. V. M. (2010). Registrar oralidades, analisar narrativas: sobre pressupostos da História Oral em Educação Matemática. Ciências Humanas e Sociais em Revista, 32, 20 35. Disponível em: https://repositorio.unesp.br/handle/11449/134443.

Leão, A. V. (2002). Magalhães Gomes, físico e humanista. Scripta, 6(11), 203-207.

Recuperado de http://periodicos.pucminas.br/index.php/scripta/article/view/12460. Acesso em 16 nov. 2021. 
DOI: 10.20396/zet.v29i00.8665754

Lüdke, M. (2005). Influências cruzadas na constituição e na expansão do sistema de pósgraduação stricto sensu em educação no Brasil. Revista Brasileira de Educação, 30, 117 123. https://doi.org/10.1590/S1413-24782005000300009.

Mendonça, A. W. P. C. (2000). A universidade no Brasil. Revista Brasileira de Educação, 14, 131-151. Disponível em: https://www.scielo.br/pdf/rbedu/n14/n14a08.pdf.

Motta, R. P. S. (2014). As universidades e o regime militar: cultura brasileira e modernização autoritária. Rio de Janeiro: Zahar.

Oliveira, J. V. \& Faria Filho, L. M. (2019). Educação e modernização: a UFMG na trajetória de um projeto modernizante (1968-1974). Revista Contemporânea de Educação, 14 (29), 193-207. Disponível em: https://revistas.ufrj.br/index.php/rce/article/view/18426.

Portelli, A. (2010). Ensaios de história oral. São Paulo: Letra e Voz.

Portelli, A. (2016). História oral como arte da escuta. São Paulo: Letra e Voz.

Resende, M. E. L., \& Neves, L. A. (1998). Universidade Federal de Minas Gerais: memórias de reitores (1961-1990). Belo Horizonte: Editora UFMG.

Saviani, D. (2008). O legado educacional do regime militar. Cadernos Cedes, 28 (76), https://doi.org/10.1590/S0101-32622008000300002.

Silva, W. L. (2012). Espelho de palavras: escrita de si, autoetnografia e ego-história. In Avelar, A. S. \& Schmidt, B. B. (Orgs.), Grafia da vida: reflexões e experiências com a escrita biográfica (pp. 39-61). São Paulo: Letra e Voz.

Universidade Federal de Minas Gerais (UFMG). Departamento de Matemática. Instituto de Ciências Exatas (ICEx). (1973). Livro de atas de reuniões da Câmara Departamental. UFMG: Belo Horizonte.

Universidade Federal de Minas Gerais (UFMG). Departamento de Matemática. Instituto de Ciências Exatas (ICEx). (1977). Livro de atas de reuniões da Câmara Departamental. UFMG: Belo Horizonte.

Veiga, L., Albano, M. C. P., Somarriba, M. M. G., \& Barbosa, M. L. de O. (1987). UFMG: trajetória de um projeto modernizante. Revista do Departamento de História, 5, 5-40.

Vieira, E. P. A. (2016). A regulamentação do trabalho docente superior posta na reorganização do ensino superior nos anos de 1960. Imagens da Educação, 6 (1), 59-67. https://doi.org/10.4025/imagenseduc.v6i1.26871291-312. 